\title{
Oral Autopsy, Facial Reconstruction and Virtopsy: an Update on Endeavors to Human Identification
}

\author{
Deepti Sharma ${ }^{1}$, George Koshy ${ }^{2}$, Sanchita Garg ${ }^{3}$, Bhushan Sharma ${ }^{4}$, Sonal Grover ${ }^{5}$, \\ Manveer Singh ${ }^{6}$ \\ ${ }^{1,5}$ Assistant Professor, ${ }^{2}$ Professor and Head, ${ }^{3,6}$ Intern, ${ }^{4}$ Associate Professor, Department of \\ Oral and Maxillofacial Pathology, Christian Dental College and Hospital, Ludhiana
}

\begin{abstract}
The analysis of unidentified human remains and collected evidences in the forensics, necessitates the adoption of multidisciplinary approach. The involvement of forensic odontologist in the forensic examination is significant as examination of oral cavity requires an oriented and skilled approach. Oral autopsy, Facial reconstruction and Virtospy are added tools in forensic kit which if judiciously used could be helpful in human identification and criminal investigation. These techniques should be encouraged by enhancing the understanding of medical/ dental experts and law enforcement agencies. This review is an attempt to provide a glimpse of advancements in the forensic medical science.
\end{abstract}

\section{INTRODUCTION}

Forensic science is no longer an abstraction; it is closely woven into the fabrics of the law enforcement agencies. It is a multidisciplinary subject which is used for probing crime scenes and gathering evidence to be used in the prosecution of offenders in the court of law. ${ }^{1}$ The word "Forensic" is derived from the Latin word "forensis" which means forum, a public place where, in Roman times, judicial proceedings were held. The intersection of forensic science and law provides new tools and methodologies for discovering the truth. ${ }^{2}$ In the past dental evidences including bite-marks, lip prints, tooth fragments, dental prosthesis as well as the DNA obtained from saliva or teeth have been overlooked and underestimated. ${ }^{3}$ But in recent years, there has been a dramatic progress in the field of forensic odontology and every trace evidence has its unique way of examination. It is thus important to recognize oral findings as substantial evidence to be acknowledged by experts. Although, presently only a very few professionals are equipped with the knowledge necessary to fully apply the potential of forensic odontology but future implies its expanded role in solving civil, criminal and family legal matters. ${ }^{4}$ Therefore, this review is an attempt to provide a glimpse of advancements in the forensic medical science.

\section{Oral autopsy}

Autopsy is derived from the Greek word autopsia, meaning "the act of seeing for oneself." It involves examination and dissection of a dead body in order to identify the deceased and determine the cause or time of death. ${ }^{5}$ The Interpol has given a disaster victim identification (DVI) guide in 1997 and revised it in 2009, which states that, "where appropriate, the examination of teeth and jaws should be carried out by a dentist with medico-legal experience". Henceforth, it is the investigator who faces the question whether or not to carry out oral autopsy. ${ }^{6}$ Oral autopsy refers to an elaborate examination of the oral cavity, as teeth are most resistant to decomposition and can be used as a reliable means of human identification. Comparison of ante-mortem and post-mortem dental records, dental profiling, examination of oral structures (tongue, mucosa, palate, teeth) and DNA extraction from teeth are some of the possible means to ascertain the identity of an individual. Also to some extent, time and cause of death can also be determined from teeth. ${ }^{7}$ The time elapsing between the death and forensic examination is crucial as the body undergoes various stages of decomposition thus compromising the overall examination. In the oral cavity, mouth opening is restricted due to rigor mortis as the muscles of mastication become stiff. Hence, certain specific dissection techniques and criterias are used to perform an accurate oral autopsy. ${ }^{8}$ 


\section{Techniques}

For intraoral examination dissection can be performed in certain ways and the technique selection for oral autopsy should be done considering the fact that minimum distortion of the soft tissues takes place, thus enabling the post-autopsy reconstruction.

- Extraoral incisions (facial dissection)- include bilateral incisions from the oral commisures to the body of the ramus, on a plane parallel with the plane of occlusion, through the masseter to bone thus permitting soft tissue reflection for better access.

- Inframandibular incision- refers to dissection of the skin inferior and medial to the mandible in a direction from the ear across the midline to the opposite ear. These approaches are followed for viewable bodies when oral cavity is inaccessible because of rigor mortis.'

The different methods for exposing the dental structures for examination and recording dental evidence involving the mandibular resection and jaw separation are Stryker Autopsy Saw Method, Pruning Shears Method, Mallet and Chisel Method (jaw resection). ${ }^{10}$

- Stryker Autopsy Saw Method : is a simple method and is comprised of cutting the soft tissues through the fat and muscles from the angle of the mandible to the midline. The incision continues to the lateral surfaces of the mandibular base so that the soft tissues of the neck can be stripped in an upward direction. The masseter muscles and the vestibular attachment are incised. The next steps involve the removal of the mandible (after the incision of the ramus and the pterygoid musculature) and maxilla can be removed, by making a incision in the most superior portion of maxilla avoiding the third molars in both incisions (Figure 1).

- Mallet and Chisel Method : a Le Fort I fracture is being induced, positioning the chisel below the zygomatic arch, high on the maxillary sinus walls bilaterally.

- Pruning Shears Method : the blade of the shears is placed within the nares and forced back into the maxillary sinus. The cut is made superiorly to the apices of the maxillary teeth. ${ }^{10}$ suggested by Fereira et $\mathrm{al}^{12}$. intend to preserve the facial anatomy even after dissection. On the other hand, Archemides screw method, extraoral incisions, inframandibular incision and the most conservative approaches.

- Archimedes Screw Method: involves the application of an Archimedes screw. The point of the screw is placed between first and second bicuspids and turned until the jaws are separated.

Conservative approach was suggested by Fereira et al. which preserved the facial anatomy even after dissection. ${ }^{12}$ In this approach, after adequately identified photographs are taken, in order to record the conditions under which the cadaver was found, the following incisions are made:

- Superior incision from tragus to other tragus of the ear including the anterior nasal spine.

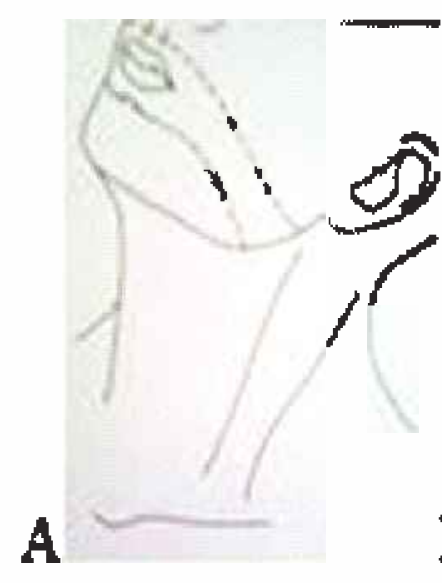

A: Perioral incision B: Soft Tissues removed
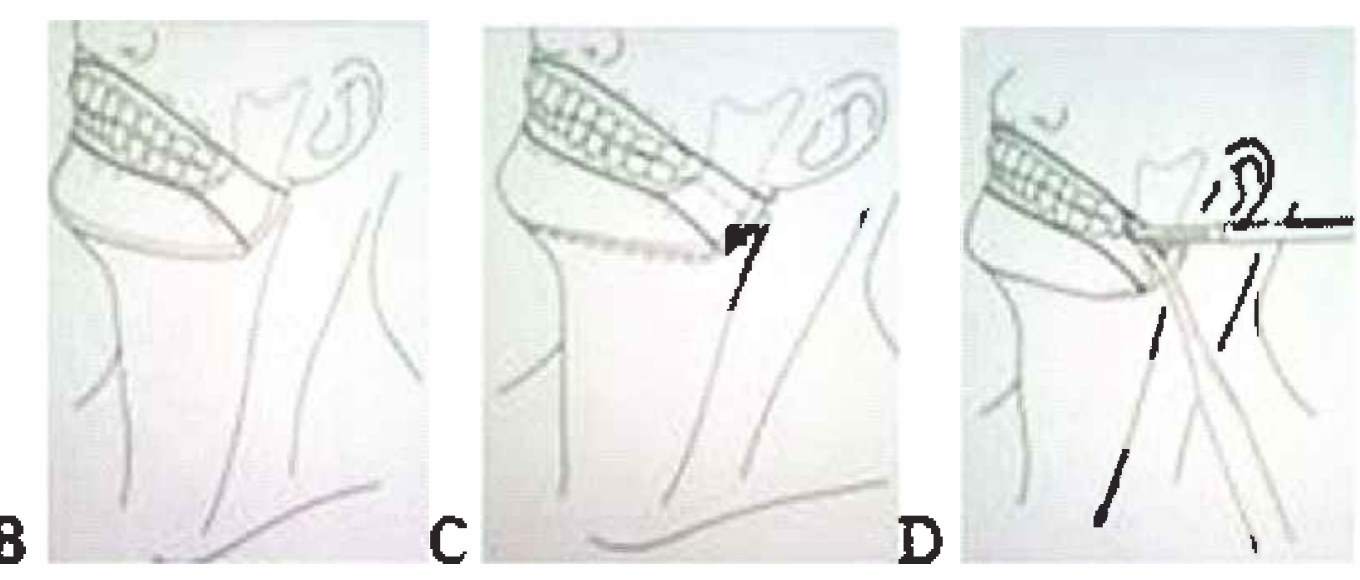

Figure 1: Different dissection techniques ${ }^{9-11}$

C: Ramus bony cut and submental-mylohyoid incision

D: Separating ramus and incision of the pterygoid muscles 
- Inferior incision from the mental eminence of the jaw, at the base of the alveolar process sideways to the body of the mandible, parallel to its inferior edge, crossing the ramus and arriving to its back edge, sectioning the masseter muscle.

- Lateral incisions, two, one on each side, joining the two aforementioned sections. After the careful removal of the lip and cheek tissues, the sectioning of the internal pterygoid muscles, the condyle and the capsular ligament of the TMJ follows. These tissues are separated directly from the periosteum in order to achieve repositioning. ${ }^{10}$ Another conservative approach had been put forwarded by Heit OF et al and is comprised of performing bilateral "C-shaped" incisions in the retromandibular region. The total length of each incision is approximately $6 \mathrm{~cm}$ in adults. The incision must follow the posterior border of the mandible from a minimum distance of two centimeters and medial pterygoid and masseter muscles and respective tendon insertions must be dissected around the mandible angle followed by linear osteotomy separating the mandible ramus to the mandible body (Figure 2).

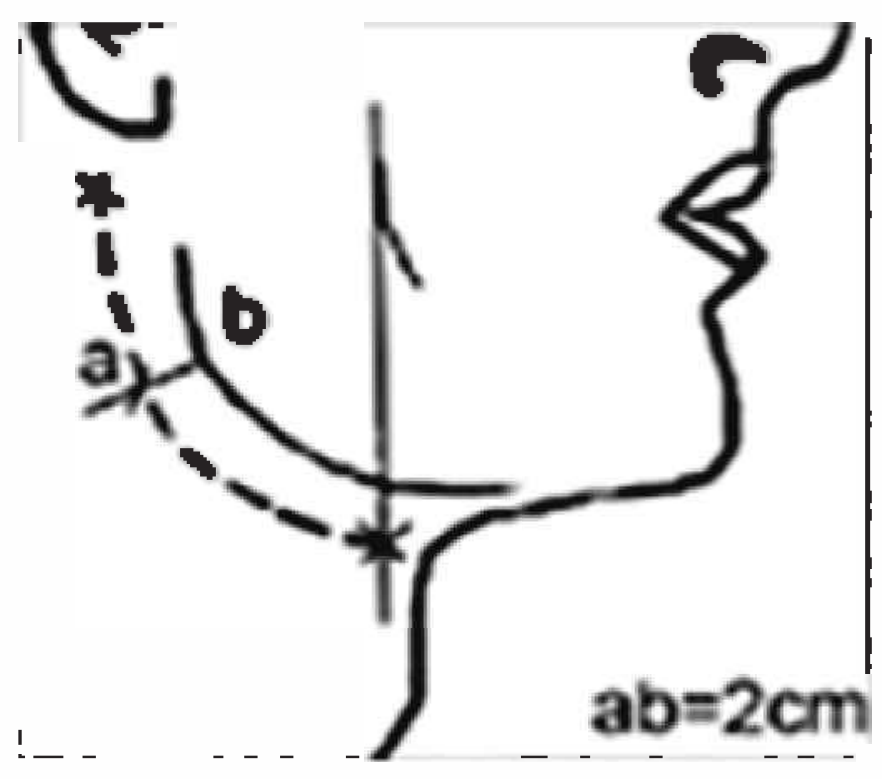

Figure 2: "C-shaped" incision in the retromandibular area Minimum $2 \mathrm{~cm}$ between the incision and the posterior limit of the mandible(ab). The vertical line indicates the anterior limit of the mandibular ramus as the inferior limit of the "C-shaped" incision. ${ }^{13}$

Gowda $\mathrm{CBK}^{7}$ also introduced a simpler technique to obtain access to oral cavity for examination (Figure 3)

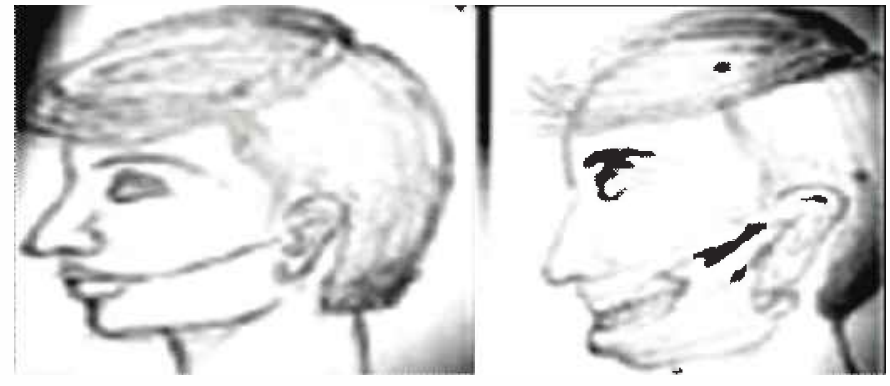

Figure 3: Incision given from angle of mouth to tragus of ear and flap is reflected

After obtaining the intraoral access, prostheses and other appliances are being removed and description of the anomalies and charting of the occlusion are followed by occlusal radiographs, if necessary. The lips and cheek tissues, the jaws, prosthesis and other appliances are removed carefully. ${ }^{11}$ Dental and soft tissue anomalies, details of the occlusion are described and occlusal radiographs, if necessary are obtained. The radiographic examination is required prior to the repositioning of the cadaver, to record the true relationship between the anatomical landmarks of the body. Photographic record of the entire procedure (pre-autopsy, during and postautopsy) should also be maintained. ${ }^{7}$ Different techniques are to be followed for infants and adults due to less intensity of rigor mortis in infants. Aka and Canturk have proposed the extraction of tooth germs by giving a semicircular incision in the jaws which provides most of the information and causes minimum intervention with anatomy. ${ }^{8}$ The different indications and uses of oral autopsy are given in table1.

\section{Facial Reconstruction}

When conventional identification methods are not helpful, facial reconstruction comes to the rescue. It is used in forensic science as well as archaeology. It is the art and science of recreation of multiple facial structures using the bony remains of the deceased. ${ }^{14}$ Historically, the first facial reconstruction was done in 1895. The technique is time tested and has passed through many phases over the $19^{\text {th }}$ and $20^{\text {th }}$ century. In 1946, five basic principles to modify the methods of reconstruction of soft tissues of the face were defined i.e. the relation of eyeball to orbit, the shape of nose tip, the ear location, the mouth width and the ear length. These parameters provide a very accurate image of any distorted cadaver to help in the identification. Thus, paving the way for using facial reconstruction as a forensic technique rather than just for archaeological purposes. ${ }^{15}$ Facial reconstruction is at best a tool for producing images that are an approximation of what a face may have looked like in life. ${ }^{16}$ 
Table 1 : Indications and Uses of Oral Autopsy ${ }^{6}$

\begin{tabular}{|c|c|}
\hline When to do oral autopsy? & WHAT DOES IT DETERMINE? \\
\hline $\begin{array}{l}\text { Unidentified cadavers which } \\
\text { are severely distorted due to } \\
\text { decomposition or fire (in case of } \\
\text { mass disasters or homicides) }\end{array}$ & $\begin{array}{l}\text { Teeth resistant to decomposition and to some extent, fire, so they can be used to } \\
\text { establish identity through specific traits and records for e.g. pink teeth are seen in } \\
\text { cases of asphyxia especially drowning, strangulation or suffocation }\end{array}$ \\
\hline Death due to strangulation & $\begin{array}{l}\text { External compression of neck- hemorrhage of tongue, Homicidal ligature } \\
\text { strangulation-conjunctival petechiae, facial, intraoral or laryngeal petechiae, } \\
\text { Smothering death- evidence of trauma extra or intra-orally, Death due to gagging- } \\
\text { presence of gag or foreign body in mouth or airway }\end{array}$ \\
\hline Cases of drowning & $\begin{array}{l}\text { Froth is expressed around the mouth and nostrils in atypical "wet" drowning. Salt } \\
\text { water may beat on the skin of the face, especially around the mouth, nose, or ears }\end{array}$ \\
\hline Sudden death & $\begin{array}{l}\text { Evidence of seizure activity in the form of lip injuries and bitemarks, especially of } \\
\text { the tongue, Gingival hyperplasia seen in patients on anti-epileptic drugs }\end{array}$ \\
\hline Child abuse cases & $\begin{array}{l}\text { Evidence of bruised or lacerated lips and gums, or tongue, inner cheek and dental } \\
\text { injuries, even scarring (in chronic abuse), Evidence of oral penetrations suggest } \\
\text { sexual abuse }\end{array}$ \\
\hline $\begin{array}{l}\text { Rape cases or sexually } \\
\text { motivated murders }\end{array}$ & $\begin{array}{l}\text { Presence of erythema, petechiae and dilated blood vessels located on the soft palate } \\
\text { alongwith ano-genital findings suggest sexual abuse }\end{array}$ \\
\hline Death due to poisoning & $\begin{array}{l}\text { Arsenic, Mercury and Cyanide poisoning- presence of burns in the mouth area or } \\
\text { face; froth on lips } \\
\text { Lead poisoning-a blue-purplish line is seen on the gums (Burton's line) } \\
\text { Cadmium poisoning-gingivitis, teeth loss and caries, and a cadmium line around } \\
\text { the necks of the teeth (yellow rings) } \\
\text { Bismuth poisoning-numerous tiny, black deposit spots on the oral and lower lip } \\
\text { mucosa } \\
\text { Drug overdose-froth in nose and mouth. Poor oral health, xerostomia, dental } \\
\text { caries, enamel erosion, and periodontal disease seen in drug addicts } \\
\text { Cannabis stomatitis-leukoedema of the oral mucosa and hyperkeratosis caused due } \\
\text { to cannabis smoking } \\
\text { Cocaine abuse-mucosal breakdown, gingival lesions, erosion of tooth surfaces, } \\
\text { and loss of palatal bone } \\
\text { Meth mouth- seen in chronic Methamphetamine users resulting in tooth loss, } \\
\text { bruxism, dry mouth }\end{array}$ \\
\hline Chemical burns & $\begin{array}{l}\text { Solid alkalis produce deep burns where they adhere to the oral mucosa } \\
\text { Liquid alkalis are easily swallowed and enter the esophagus, produce liquefaction } \\
\text { necrosis, and expose deeper layers of tissue to the caustic agent thus producing } \\
\text { much more extensive injuries } \\
\text { Acids produce burns on the tongue, and tanning scars on commissures and mucosa } \\
\text { of the lips }\end{array}$ \\
\hline $\begin{array}{l}\text { Death caused due to shooting } \\
\text { or explosives }\end{array}$ & $\begin{array}{l}\text { Self-inflicted or homicidal cases - intraoral wounds are associated with soot } \\
\text { deposition on the lips, teeth (tongue is more involved in suicidal cases) } \\
\text { Gun powder residue from intraoral wounds } \\
\text { Extensive fractures of the skull and tears around the nose, eyes, and mouth. } \\
\text { Perioral "stretch" lacerations are limited to mouth entries }\end{array}$ \\
\hline
\end{tabular}




\section{Techniques}

Forensic facial reconstruction (FFR), or facial approximation is based on exclusive facial morphological characteristics and anatomical landmarks of human face. The accuracy of positive identification and enhanced chances of recognition could be achieved by evaluating oral and paraoral parameters and correlating the surface soft tissues of the face and bony structures of the skull. ${ }^{17}$

Many criminal cases have also been solved using this scientific art. Identification has been done in the past from Copernicus to Shakespeare and Sheena Bora case in 2015 (India). ${ }^{18}$ Techniques changed over the centuries but the ultimate goal was to create a convincing likeness of the dead. The methods may involve photographic superimposition or modeling a face on the skull replica with clay or plasticine and computer graphic simulations [two dimensional (2D) and three dimensional (3D) reconstruction ${ }^{19}$ Details are given in table 2.

In vivo reconstruction of the face is possible by accurate assessment of facial soft tissue thickness at selected anatomical landmarks and knowledge of morphological/ anatomical features. ${ }^{20}$ The more reproducible facial sculpting can also be done by utilizing 3D computer technology employing laser scanned 3D skull images and special computer softwares and programs. ${ }^{21}$

The use of antemortem photographs to permit facial superimposition of skeletal and teeth features have been used in case of identification. The technique demands the availability of suitable antemortem photographs showing the teeth. Often, angulations and magnifications impose difficulties in positioning the images. ${ }^{22}$ This necessitates the maintenance of antemortem photographic and

Table 2. Facial reconstruction techniques ${ }^{15,16}$

\begin{tabular}{|c|c|c|}
\hline Superimposition & Two dimensional & Three dimensional \\
\hline \multirow[t]{2}{*}{$\begin{array}{l}\text { Comparison of the } \\
\text { images of the skull with } \\
\text { submitted photographs. } \\
\text { 2. Video: The method } \\
\text { involves focusing of } \\
\text { video cameras onto } \\
\text { different images that can } \\
\text { then be merged and } \\
\text { displayed on a computer } \\
\text { screen. } \\
\text { It requires the images of the } \\
\text { 3-D reconstruction, the } \\
\text { superimposition and the } \\
\text { actual skull to compare the } \\
\text { positions and sizes of facial } \\
\text { features. }\end{array}$} & $\begin{array}{l}\text { 1. Recreating the facial profile from the } \\
\text { skull by using soft tissue depth } \\
\text { estimates. } \\
\text { 2. It was inspired from the idea that the } \\
\text { relative positions of facial features are } \\
\text { dictated by the skull and hypothesized } \\
\text { that an individual's face could be } \\
\text { formed by substituting an "average" } \\
\text { face onto the skull. } \\
\text { 3. Used soft-tissue depth markers and } \\
\text { "average" face was computer- } \\
\text { generated onto a known skull. } \\
\text { The method requires an artist, } \\
\text { anthropologist and medical expert to } \\
\text { work together. }\end{array}$ & $\begin{array}{l}\text { Manualmethods: } \\
\text { 1. Anthropometerical American Method/ } \\
\text { Tissue Depth Method: In this, fine } \\
\text { measurements of soft tissue depth were } \\
\text { obtained by the use of needles, X-rays or } \\
\text { ultrasound. } \\
\text { 2. Anatomical Russian Method: } \\
\text { Soft tissue depth data was not } \\
\text { considered and reconstruction was done } \\
\text { by shaping muscles, glands and cartilage } \\
\text { onto the skull layer bylayer } \\
\text { 3. Combination Manchester Method/ } \\
\text { British Method: Most accepted method } \\
\text { for facial reconstruction today. In this, } \\
\text { both soft tissue thickness and facial } \\
\text { muscles are considered. }\end{array}$ \\
\hline & $\begin{array}{l}\text { Advances } \\
\text {--Computer software programs } \\
\text { like Computer Assisted Recovery } \\
\text { Enhancement System (CARESTM) or } \\
\text { CARES and Forensic Anthropology } \\
\text { Computer Enhancement System (FACES) } \\
\text { etc produce 2D reconstruction which can } \\
\text { be edited and manipulated. } \\
\text {--Based on capturing and digitalizing } \\
\text { radiographs, photographs and images of } \\
\text { skulls and producing an electronically } \\
\text { altered version of the image. } \\
\text { Fast and accurate reconstruction process } \\
\text { and produce more generic images }\end{array}$ & $\begin{array}{l}\text { Computerized 3D FFR: 3D computerized } \\
\text { models are made using manual clay model } \\
\text { techniques. } \\
\text { Computerized systems } \\
\text {--3D animation software: to model the face } \\
\text { onto the skull } \\
\text {--Virtual sculpture system with Haptic } \\
\text { feedback } \\
\text {--Phantom Desktop TM Haptic Device } \\
\text {--Sensable Technologies }\end{array}$ \\
\hline
\end{tabular}


radiographic images (medical/dental). Now automated procedures are followed so that multiple recreations can be seen at a moment. The commonly associated problems with facial reconstruction methods are subjectivity, insufficient tissue thickness data and lack of methodological standardization which could be gradually improved with expertise. ${ }^{23}$

\section{Forensic imaging techniques including Virtopsy as a budding science}

Dental and craniofacial imaging, digital photography and various computer softwares play a very significant role in forensic orthodontics. Digital photography allows for immediate retakes and duplicates of the images when needed. Digitized data can be reused leaving behind the additional cost of film or its chemical processing. Digitized images enable clear visualization and enhanced manipulation. They are basically used to store, sort and match antemortem and postmortem records in a speedy and accurate manner. ${ }^{24}$ An upcoming newer approach, forensic 3-dimensional photogrammetry is used for the evaluation of a forensically relevant object, such as a bitemark or other patterned injuries and it depends primarily on the proficiency in the preparation and subsequent photographic recording of these objects. ${ }^{25}$

Several radiological techniques including CT (computed tomography), MRI (magnetic resonance imaging) and CBCT (Cone beam Computed tomography) can also be used to assist in both individual and general identification, including determination of gender, ethnic group and age. Digital radiographic images can be enhanced for optimal viewing thus permitting side-by-side digital comparisons of antemortem and postmortem radiographs. Radiographs provide details, which may not be registered by clinical examination, for example, the shapes of restorations, bases under restorations, dental and radicular shapes, endodontic treatments, and anatomy of the maxillary sinuses. ${ }^{26}$ As the clinical use of cross-sectional imaging methods such as CT and MRI has increased, many forensic dentists also have begun to evaluate these technologies as potential tools in craniofacial reconstruction. The use of CT has evolved into the "virtual autopsy" ("virtopsy") concept. ${ }^{27}$ 3D imaging is boon for forensic procedures and virtual autopsy commences a new phase in forensic investigations. It allows exploration of inside of the human body and challenges the myth that cause of the death could be ascertained only by cutting a dead body open. ${ }^{28}$ The method is already in vogue successfully to complement conventional autopsies. It is an alternative to invasive surgical procedures and uses latest radiological techniques like CT, MRI, and threedimensional (3D) imaging for the examination of cadavers. ${ }^{29}$ Sometimes with charred bodies and damaged oral cavities virtopsy becomes a quick, reliable way for getting postmortem records. ${ }^{30}$

Virtopsy basically consists of (a) body volume documentation and analysis using CT, MR imaging, and microradiology, (b) 3D body surface documentation using forensic photogrammetry and 3D optical scanning. The resulting data set contains high-resolution 3D colorencoded documentation of the body surface and 3D volume documentation of the interior of the body. ${ }^{31}$ Currently dentistry is also heading for non-invasive treatment thus making identification based on restorations more difficult. The identification relying on the morphology of pulp chambers, root arrangement and periodontal status is gaining importance. The principle of triangulation forms the basis of $3 \mathrm{D}$ imaging in virtopsy. ${ }^{32}$ Other advantages over the conventional autopsies include effective visualization and localization of the fracture lines, depth of the foreign body, primary and secondary traumas and no risk of cadaver contamination. However, compromised physiological and tactile senses of an anatomical pathologist like smell, texture and color and high cost are its few limitations. ${ }^{33}$ Virtopsy is a new addition in the list of forensic examination techniques with a promising future ahead. Through digital data archiving and quality assurance, this technique provides an objective and accurate documentation of forensic findings for testimony in court. ${ }^{28}$

With the advancement of newer technologies, more accurate information is obtained for identification as well as in the facial reconstruction of the unknown deceasesd person. Forensic research requires the application of reliable identification methods for unidentified individuals, among which the dental analysis has prime importance. Post mortem examinations or autopsies (necropsy) are done by pathologists or medical doctors who have received specialty training for it. Oral autopsy has been proved as an adjunct in the identification process alongwith necropsy. ${ }^{34}$ Reconstruction techniques have been used as a last resort not only in criminal cases but also for purpose of anthropological studies. Little is known about the exact nature of the relationship between the hard and soft tissues of the human face. Although many techniques have been developed, there is a debate over the usefulness of the tissue depth measurements done on 
cadavers. ${ }^{14}$ However, researchers have concluded that profound knowledge of the anatomy and morphology of the oral cavity may contribute to increasing the precision of forensic facial reconstructions and help with human identification. ${ }^{17}$ Inspired by rapid technological improvements, researchers in several countries have been exploring the possibility that medical imagingin particular, MRI and CT scansmight substitute a "virtual autopsy" for the more traditional variety. Modern cross-sectional imaging techniques can supplement and may even partially replace traditional autopsy. Computed tomography (CT) is the imaging modality of choice for two and threedimensional documentation and analysis of autopsy findings. Magnetic resonance (MR) imaging has had a greater impact in demonstrating soft-tissue injury, organ trauma, and nontraumatic conditions. ${ }^{26,27,31}$

\section{CONCLUSION}

Oral autopsy is more rapid and cost effective as compared to DNA analysis. Also, facial reconstruction can be used in cases where DNA analysis is inconclusive. Virtual autopsy causes minimum distortion of the cadaver. These techniques if practiced during post-mortem examination can provide useful information.

\section{REFERENCES}

1. Kaur G, Chanana S. Forensic odontology and its Indian perspectives. JPAFMAT 2009; 9(1):21-3.

2. Jaybhaye AS. Role of forensic expert in crime Investigation - the Indian perspective. IJARLS 2012;1(3):1-10.

3. Verma AK, Kumar S, Rathore S, Pandey A.Role of dental expert in forensic Odontology. Nat J MaxillofacSurg 2014; 5(1):2-5.

4. Avon SL. Forensic Odontology: The Roles and Responsibilities of the Dentist. J Can Dent Assoc 2004; 70(7):453 8.

5. Silas OA, Adoga AA, Manasseh AN, Echejoh GO, Mandong BM, Silas RO. The Role of Necropsy in Diagnostic Dilemmas as Seen in a Tertiary Hospital in North Central Nigeria. J Trop Med 2009;2009: 1-3.

6. Fonseca GM, Cantín M, Lucena J. Forensic dentistry as a morphological exercise in the medico-legal investigation of death. Int J Morphol 2013; 31(2):399-408, 2013.

7. Gowda CBK, Mohan CV, Hemavathi. Oral autopsy: A simple, faster procedure for total visualization of oral cavity. J Forensic Dent Sci 2016;8:103-7.

8. Aka PS, Canturk N. Aka Canturk Oral Autopsy Method for the Dental Identification of Fetus and Infant Cases.Forensic Med Anat Res 2014, 2, 48-50.

9. Stavrianos C, Dietrich EM, Stavrianos I, Petalotis N. The
Role of Dentistry in the Management of Mass Disasters and Bioterrorism. Acta Stomatol Croat 2010; 44(2):110-19.

10. Herschaft EE, Alder ME,Ord DK, Rawson RD, Smith ES. Manual of forensic odontology; ed $4^{\text {th }}$.American society of forensic odontology. pp43-44.

11. Sperber N. Forensic Odontology. In: Caplan HY, Frank RS, editors. Medicolegal death investigation: in the forensic sciences. Colorado Springs, CO: The Forensic Sciences Foundation Press; 1999.p. 249-54.

12. Fereira J, Ortega A, Avila A, Espina A, Leendertz R, Barrios F. Oral autopsy of unidentified burned human remains. A new procedure. Am J Forensic Med Pathol 1997;18(3):306-11.

13. Heit OF, Silva RF, Franco A. Improving traditional dental autopsies in postmortem examinations of intraoral gunshot wounds. J Forensic Legal Med 2014; 23:87-90.

14. Tedeschi-Oliveira SV, Melani RF, de Almeida NH, de Paiva LA. Facial soft tissue thickness of Brazilian adults. Forensic Sci Int 2009; 193:127e1-127e7.

15. Gupta S, Gupta V, Vij H, VijR,Tyagi N. Forensic Facial Reconstruction: The Final Frontier. J Clin Diagn Res 2015; 9(9): 26-8.

16. Omstead J. Facial reconstruction.Uni West Ont Anthrol. 2011;10(1):37-46.

17. Dias PEM, Miranda GE, Beaini TL, Melani RFH. Practical application of anatomy of the oral cavity in forensic facial reconstruction. PLoS ONE 2016; 11(9): 1-16.

18. Deshpande S. Sheena Bora case: How skull-face superimposition process identified remains. The Times of India. Nov 252015.

19. Hayes S, Taylor R, Paterson A. Forensic facial approximation: an overview of current methods used at the victorian institute of forensic medicine/victoria police criminal identification squad. J Forensic Odontostomatol 2005;23:45-50.

20. Stavrianos C, Kokkas A, Andreopoulos E, Eliades A. Applications of Forensic Dentistry: Part -1 . Research Journal of Medical Sciences 2010;4(3): 179-86.

21. Wilkinson C. Computerized forensic facial reconstruction. A review of current systems. Forens Sci Med Pathol 2005; 1(3): 173-77.

22. Carl KK Leung. Forensic Odontology. Dental Bulletin 2008;13(11):16-20.

23. Wilkinson C. Facial reconstruction - anatomical art or artistic anatomy? JAnat 2010;216:235-50.

24. Balaji N, Senapati S, Sumathi MK. Forensic Digital Photography: A Review. Int J Dent Med Res 2014;1(3):132-5.

25. Thali MJ , Braun M, Markwalder TH, Brueschweiler W, 
Zollinger U, Malik NJ etal. Bite mark documentation and analysis: the forensic 3D/CAD supported photogrammetry approach. Forensic SciInt 2003;135:115-121.

26. Jawaid M, Amir A, Shahnawaz K, Qamar Y, Upadhay P, Singh J. Maxillofacial imaging in forensic science: a newer approach. Int J Contemp Med Res 2016;3(8):2491-95.

27. Kumar R, Athota A, Rastogi T, Karumuri SK. Forensic radiology: An emerging tool in identification. J Indian Acad Oral Med Radiol 2015;27:416-22.

28. Tejaswi KB, Periya AH. Virtopsy (virtual autopsy): A new phase in forensic investigation. J Forensic Dent Sci 2013; 5(2): $146-48$.

29. Patowary AJ. Virtopsy: One Step Forward In The Field Of Forensic Medicine - A Review. J Indian Acad Forensic Med;30(1):32-6.

30. doRosário Junior AF, Couto Souza PH, Coudyzer W, Thevissen P, Willam G, Jacobs R. Virtual autopsy in forensic sciences and its applications in the forensic odontology.Rev Odonto Cienc 2012;27:5-9.

31. Dirnhofer R, Jackowaski C, Vock P, Potter K, Thali MJ.Virtopsy: Minimally Invasive, Imaging guided Virtual Autopsy. Radiographics 2006;26(5): 1305-33.
32. Thali MJ, Jackowaski C, Oesterhelweg L, Ross SG, Dirnhofer R. Virtopsy: The Swiss virtual autopsy approach. Leg Med(Tokyo) 2007; 9:100-4.

33. Dumbrava DP, Anitan S, Siserman C, Fulga I, Opincaru I. Virtopsy: An alternative to the conventional autops. Rom J Leg Med 2010;18:75-8.

34. Mahanta P. The Medico-Legal Autopsy-It's Religious and Social Attitudes. J Indian Acad Forensic Med 2010; 32(2):183-7.

\section{Corresponding Author}

Dr Deepti Sharma, Assistant Professor, Department of Oral and Maxillofacial Pathology, Christian Dental College and Hospital, Ludhiana .

e-mail:deepti_dentist@yahoo.co.in 